\title{
Is the level of cleanliness using segmental Boston bowel preparation scale associated with a higher adenoma detection rate?
}

\author{
Adike Abimbolaa ${ }^{a}$, Buras Matthew R. ${ }^{b}$, Gurudu Suryakanth R. ${ }^{a}$, Leighton Jonathan A. ${ }^{a}$, \\ Faigel Douglas O. ${ }^{a}$, Ruff Kevin C. ${ }^{a}$, Umar Sarah B. ${ }^{a}$, Ramirez Francisco C. ${ }^{a}$ \\ Mayo Clinic, Scottsdale, AZ, USA
}

Abstract

\begin{abstract}
Background The impact of Boston bowel preparation scale (BBPS) scores on the adenoma detection rate (ADR) in each segment has not been adequately addressed. The aim of this study was to determine the association between segmental or overall ADR and serrated polyp detection rate (SDR) with segmental and total BBPS scores.
\end{abstract}

Methods All outpatient screening colonoscopies with documented BBPS scores were retrospectively reviewed at a tertiary institution from January to December 2013. Chi-square tests and logistic regression were used to analyze the detection rates of adenomas and serrated polyps with bowel prep scores. Odds ratios were calculated using logistic regression that controlled for withdrawal time, age, body mass index, diabetes status and sex.

Results We analyzed 1991 colonoscopies. The overall ADR was 37.5\% (95\% confidence interval $[\mathrm{CI}], 35.3-39.6)$. There was a significant difference in the overall ADR, and in SDR across all bowel category groups, with total BBPS scores of 8 and 9 having lower detection rates than scores of 5 , 6 and 7. As the quality of bowel preparation increased, there was a statistical decrease in the ADR (odds ratio [OR] 0.79 [CI 0.66-0.94], $\mathrm{P}=0.04$ ) of the right colon, while in the left colon, there was a statistical decrease in SDR (OR 0.78, [CI 0.65-0.92] $\mathrm{P}=0.019)$.

Conclusion Segmental ADR and SDR both decreased as prep scores increased, decreasing notably in patients with excellent prep scores of 8 and 9. A possible explanation for this unexpected discrepancy may be related to longer and better visualization of the mucosa when cleansing and suctioning is necessary.

Keywords Adenoma detection rate, serrated polyp detection rate, Boston bowel preparation scale score

Ann Gastroenterol 2018; 31 (1): 1-8

\section{Introduction}

The quality of colon cleansing is a key determinant of colonoscopy quality as it relates to polyp detection rates, complete

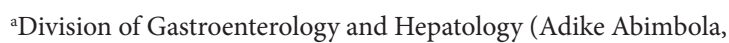
Gurudu Suryakanth, Leighton Jonathan, Faigel Douglas, Ruff Kevin,

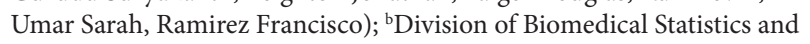
Informatics (Buras Matthew), Mayo Clinic, Scottsdale, AZ, USA

Conflict of interests: None

Correspondence to: Francisco Ramirez, Division of Gastroenterology and Hepatology, Mayo Clinic, 13400 E Shea Blvd, Scottsdale AZ 85259, USA, e-mail: ramirez.francisco@mayo.edu

Received 20 September 2017; accepted 18 December 2017; published online 31 Januray 2018

DOI: https://doi.org/10.20524/aog.2018.0231 examinations and overall efficiency. Inadequate preparations lead to lower adenoma detection rates (ADRs), longer insertion and withdrawal times, repeat colonoscopy, and increased costs [1-3]. Thus, it is intuitively assumed that the better a colon preparation is, the higher the ADR will be [4]. More recently, however, a few studies have shown that the quality of colon preparation is not necessarily associated with the ADR [5-7].

The Boston bowel preparation scale (BBPS) is a widely used bowel cleanliness scoring system. Each colon segment-right, transverse and left colon-is scored from 0-3, after washing the colon wall during the procedure. The overall score is calculated by adding scores from all three segments, with 9 being the highest score, representing an excellent prep. The BBPS is a validated prep scoring system that has been shown to have good intra- and interobserver reliability [8-10]. Furthermore, a BPPS segment score of less than 2 has been associated with missed lesions [11]. 
The impact of the BBPS and ADR at each individual colon segment has not been previously addressed for all BBPS scores. In this study, we used the total and segmental BBPS scores to analyze the association between the quality of the preparation and the corresponding $\mathrm{ADR}$, serrated polyp detection rate (SDR), advanced adenoma detection rate (AADR), and polyp detection rate (PDR).

The primary objective of this study was to determine the association between the segmental or overall ADR and SDR and the segmental and total BBPS scores. In addition, we sought to determine the association between the segmental or overall AADR and PDR and the segmental and total BBPS scores.

\section{Patients and methods}

We performed a retrospective review of all screening colonoscopies performed at an academic center by 21 boardcertified gastroenterologists, with and without trainees, from January to December 2013. The study was approved by the Mayo Clinic Institutional Review Board.

We collected demographic information, including patients' sex, age, body mass index (BMI), and diabetes mellitus status. We excluded all incomplete colonoscopies, i.e., colonoscopies without cecal intubation. We have been using the BBPS scoring system for colon preparation at our institution since 2011, and all endoscopists at our institution know how to use this scoring system. In addition, pictorial description of each BBPS score is provided in each room in our endoscopy suite. We excluded colonoscopies without a BBPS score. For each colonoscopy, we collected the BBPS per segment (right colon, transverse and left colon segments) and the number of polyps removed from each segment. We calculated detection rates for each total BBPS value (scores 1-9). In addition, we also assigned categories to total BBPS score, as follows: poor (1-4), fair (5), good (6-7) and excellent (8-9). BBPS segment scores were assigned as poor (0), fair (1), good (2), and excellent (3). As the number of segmental observations with poor scores was limited, we combined poor and fair bowel preparations.

We defined the right colon as the cecum, ascending colon, and hepatic flexure. The left colon was defined as the splenic flexure, descending colon, sigmoid colon and rectum. We recorded the time of cecal intubation and the time at withdrawal. Withdrawal time was calculated as the difference between the time to cecal intubation from the time of scope removal. All pathology reports from each colonoscopy were reviewed. The type and size of polyps identified from each colon segment was recorded. Advanced adenoma was defined as polyps $\geq 10 \mathrm{~mm}$, villous or tubulovillous adenomas, or polyps with high grade dysplasia or carcinomas. Serrated polyps included traditional serrated adenomas, sessile serrated adenomas, and hyperplastic polyps, following the World Health Organization's classification of tumors of the colon and rectum [12]. SDR was calculated with and without inclusion of hyperplastic polyps.

$\mathrm{ADR}$ was calculated as the number of colonoscopies with at least one adenoma divided by the total number of colonoscopies. SDR was calculated as the number of colonoscopies with at least one serrated polyp divided by the total number of colonoscopies. AADR was calculated as the number of colonoscopies with at least one advanced adenoma divided by the total number of colonoscopies. PDR was calculated as the number of colonoscopies with at least one polyp divided by the total number of colonoscopies. Overall and segmental ADR, SDR, AADR, and PDR were calculated by total and segmental prep scores and by location.

\section{Statistical analysis}

Exact binomial confidence intervals were computed for ADR, SDR, AADR, and PDR at the 95\% level of confidence. Chi-squared tests were used to individually analyze the rates across bowel prep categories. Logistic regression was used to individually analyze the detection rates of adenomas, serrated polyps, advanced adenomas and all polyps across bowel prep scores using BBPS as a continuous variable. In addition, the logistic regression analyses were repeated to control, for age, sex, BMI, diabetes status, and withdrawal time. Wald confidence intervals for the odds ratios (OR) were calculated at the $95 \%$ confidence level. Interquartile range (IQR) was calculated as the difference between the $75^{\text {th }}$ percentile and the $25^{\text {th }}$ percentile. A Kruskal-Wallis test was implemented to analyze the difference in withdrawal time between bowel prep categories. To correct for multiple testing, the unadjusted $\mathrm{P}$-values were calculated along with $\mathrm{P}$-values that have been adjusted to reflect a false discovery rate of 0.05 . P-values less than 0.05 were considered statistically significant; all analyses were performed using SAS 9.4 (SAS Institute Inc.; Cary, NC).

\section{Results}

There were 2203 complete colonoscopies. Colonoscopies without a prep description $(n=20)$ and those without a BBPS score $(n=192)$ were excluded. A total of 1991 patients were included in this study: 1022 (51\%) were female, 969 (49\%) were male. The overall mean age $( \pm \mathrm{SD})$ was $59 \pm 8.9$ years (males $59.03 \pm 9.2$; females $58.97 \pm 13.4$ ). Using the total BBPS scores, 134 colonoscopies $(6.7 \%)$ had a poor prep, 272 colonoscopies (13.7\%) had a fair prep, 1033 (51.9\%) had a good prep and $552(27.7 \%)$ had an excellent prep; 1 patient had a total BBPS of $1(0.05 \%), 4$ patients had a total BBPS of $2(0.2 \%), 24$ patients had a total BBPS of $3(1.21 \%), 105$ patients had a BBPS of $4(5.27 \%)$, 272 patients had a total BBPS of 5 (13.66\%), 567 patients had a total BBPS of $6(28.48 \%), 466$ patients had a total of BBPS of 7 (23.41\%), 339 patients had a total BBPS of $8(17.03 \%)$, and 213 patients had a total BBPS of $9(10.7 \%)$. The overall ADR was $37.5 \%$ (95\% confidence interval [CI] 35.3-39.6), which is $12.5 \%$ above the current target ADR benchmark.

Table 1 shows that there is a significant decrease in the ADR, SDR (with hyperplastic polyps) and PDR amongst bowel preparation scores using BBPS as a continuous variate, as the bowel prep score increased. Fig. 1 shows that BBPS scores of 5, 6 
and 7 had higher ADRs than scores of 8 and 9. There was a high detection rate of $50 \%$ in patients with a total BBPS score of 2 , limited by the very small sample size of 4 colonoscopies with a total BBPS of $2(0.2 \%)$. Table 2 shows that there was a significant difference in the ADR, SDR (with hyperplastic polyps), and PDR, with a score of excellent having a significantly lower detection rate than the other bowel preparation categories (good and poor/fair). The estimates of ADR, AADR, and SDR (without hyperplastic polyps) were highest for prep scores of good, while the estimates of PDR and SDR (with hyperplastic polyps) were highest for prep scores of poor/fair.

Table 1 Overall adenoma detection rate (ADR), advanced adenoma detection rate (AADR), serrated polyp detection rate (SDR), and polyp detection rate (PDR) by bowel prep score

\begin{tabular}{lcc}
\hline Overall detection rate & Odds ratio & P-value \\
\hline AADR & 0.88 & 0.09 \\
$95 \% \mathrm{CI}$ & $(0.78-0.99)$ & \\
ADR & 0.9 & 0.01 \\
$95 \% \mathrm{CI}$ & $(0.85-0.96)$ & \\
SDR w/ HP & 0.9 & 0.02 \\
95\%CI & $(0.84-0.96)$ & \\
SDR w/o HP & 0.98 & 0.81 \\
$95 \% \mathrm{CI}$ & $(0.88-1.10)$ & \\
\hline PDR & 0.86 & 0.02 \\
$95 \% \mathrm{CI}$ & $(0.81-0.92)$ & \\
\hline
\end{tabular}

${ }^{1}$ Univariate logistic regression with Boston bowel preparation scale as a continuous covariate, ${ }^{2} \mathrm{P}$-values have been adjusted to reflect a false discovery rate of 0.05

CI, confidence interval; SDR $w / H P$, serrated polyp detection rate with hyperplastic polyps; SDR w/o HP, serrated polyp detection rate without hyperplastic polyps
Tables 3 and 4 show the AADR, ADR and SDR (with and without hyperplastic polyps) for each colon segment. Table 3 shows the odds ratios for each colon segment using BBPS as a continuous variable, with a significant decrease in the odds of an adenoma being detected in the right colon (OR 0.79 [CI 0.66-0.94), $\mathrm{P}=0.04$ ), a significant decrease in the odds of a serrated polyp with hyperplastic polyps being detected in the left colon (OR 0.78, [CI 0.65-0.92] $\mathrm{P}=0.019$ ) and a significant decrease in the odds of an advanced adenoma being detected in the transverse colon (OR 0.37 [CI 0.17-0.8), P=0.04) for every unit increase in BBPS. Table 4 shows that there was a significant difference in the ADR in the right colon, with the ADR dropping significantly with an excellent bowel prep score $(\mathrm{P}=0.045)$. There was a significant difference in the SDR (with hyperplastic polyps) in the left colon; the SDR again dropped significantly, with an excellent prep score having the lowest estimated detection rate $(\mathrm{P}=0.041)$.

In Tables 5 and 6, we used logistic regression to adjust for withdrawal time, age, BMI, presence of diabetes mellitus, and sex, using BBPS as a continuous variable. Our results remained consistent, with detection rates of ADR, SDR (with hyperplastic polyps), and PDR decreasing as the total BBPS score increased.

The poor/fair prep score category was associated with a median withdrawal time of $12 \mathrm{~min}$ (range 2-42, IQR $7 \mathrm{~min}$ ), good was $12 \mathrm{~min}$ (range 3-65, IQR $6 \mathrm{~min}$ ) and excellent was $10 \mathrm{~min}$ (range 3-74, IQR $5 \mathrm{~min}$ ). To further support our findings, we compared withdrawal times between bowel prep score categories of poor/fair, good and excellent and found that withdrawal time differed significantly (Kruskal-Wallis, $\mathrm{P}<0.001)$. The withdrawal time did not differ significantly between prep scores of good and poor/fair $(\mathrm{P}=0.295)$, but was significantly different between prep scores of excellent and good $(\mathrm{P}<0.0001)$ and between excellent and poor/fair (WilcoxonMann-Whitney, $\mathrm{P}=0.005)$. There was also a significant association between ADR and withdrawal time. Colonoscopies

Table 2 Overall adenoma detection rate (ADR), advanced adenoma detection rate (AADR), serrated polyp detection rate (SDR), and polyp detection rate (PDR) by bowel prep categories

\begin{tabular}{|c|c|c|c|c|c|c|c|c|c|}
\hline \multirow{2}{*}{$\begin{array}{l}\begin{array}{l}\text { Overall } \\
\text { detection rate }\end{array} \\
\text { AADR }(\%)\end{array}$} & \multicolumn{2}{|c|}{ Poor / Fair } & \multicolumn{2}{|c|}{ Good } & \multicolumn{2}{|c|}{ Excellent } & \multicolumn{2}{|c|}{ Total } & \multirow{2}{*}{$\begin{array}{c}\text { P-value } \mathrm{e}^{1,2} \\
0.09\end{array}$} \\
\hline & $31 / 406$ & $7.6 \%$ & $87 / 1033$ & $8.4 \%$ & $27 / 552$ & $4.9 \%$ & $145 / 1991$ & $7.3 \%$ & \\
\hline 95\%CI (\%) & $(5.3-10.7)$ & & $(6.8-10.3)$ & & $(3.3-7.0)$ & & $(6.2-8.5)$ & & \\
\hline $\operatorname{ADR}(\%)$ & $162 / 406$ & $39.9 \%$ & $414 / 1033$ & $40.1 \%$ & $170 / 552$ & $30.8 \%$ & $746 / 1991$ & $37.5 \%$ & 0.01 \\
\hline 95\%CI (\%) & $(35.1-44.9)$ & & $(37.1-43.1)$ & & $(27.0-34.8)$ & & $(35.3-39.6)$ & & \\
\hline SDR w/ HP (\%) & $129 / 406$ & $31.8 \%$ & $302 / 1033$ & $29.2 \%$ & $124 / 552$ & $22.5 \%$ & $555 / 1991$ & $27.9 \%$ & 0.01 \\
\hline 95\%CI (\%) & $(27.3-36.6)$ & & $(26.5-32.1)$ & & $(19.1-26.2)$ & & $(25.9-29.9)$ & & \\
\hline SDR w/o HP (\%) & $29 / 406$ & $7.1 \%$ & $93 / 1033$ & $9 \%$ & $39 / 552$ & $7.1 \%$ & $161 / 1991$ & $8.1 \%$ & 0.47 \\
\hline 95\%CI (\%) & $(4.8-10.1)$ & & $(7.3-10.9)$ & & $(5.1-9.5)$ & & $(6.9-9.4)$ & & \\
\hline PDR (\%) & $255 / 406$ & $62.8 \%$ & $599 / 1033$ & $58 \%$ & $265 / 552$ & $48 \%$ & $1119 / 1991$ & $56.2 \%$ & 0.02 \\
\hline 95\%CI (\%) & $(57.9-67.5)$ & & $(54.9-61.0)$ & & $(43.8-52.3)$ & & (54.0-58.4) & & \\
\hline
\end{tabular}

${ }^{1}$ Chi-squared test, ${ }^{2} \mathrm{P}$-values have been adjusted to reflect a false discovery rate of 0.05

CI, confidence interval; SDR w/ HP, serrated polyp detection rate with hyperplastic polyps; SDR w/o HP, serrated polyp detection rate without hyperplastic polyps 


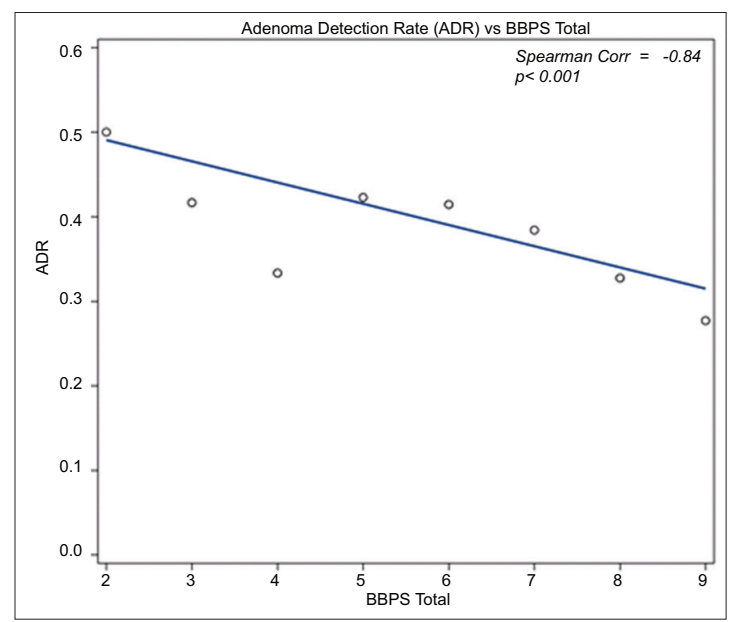

Figure 1 Boston bowel preparation scale (BBPS) as a continuous variable with adenoma detection rate (ADR) $n=1990$, as the outlier observation was removed (BBPS=1). ADR weighted by frequency of the $B B P S$

with an adenoma detected had a significantly higher median withdrawal time of $14 \mathrm{~min}$ (range 2-74, IQR $7 \mathrm{~min}$ ) compared to examinations without an adenoma detected, where the median withdrawal time was $10 \mathrm{~min}$ (range 2-37, IQR $5 \mathrm{~min}$; Wilcoxon-Mann-Whitney, $\mathrm{P}<0.001$ ). Overall (for ADR, SDR with hyperplastic polyps and PDR), BBPS scores of poor/ fair and good had significantly higher withdrawal times than an excellent prep. Finally, we also analyzed the effect of our observation on colonoscopies performed by trainees at our institution. We found no significant difference in the detection rates of $\mathrm{AADR}$ (chi-square $\mathrm{P}=0.44), \mathrm{ADR}$ (chi-square $\mathrm{P}=0.48$ ), SDR with hyperplastic polyps (chi-square $\mathrm{P}=0.85$ ), SDR without hyperplastic polyps (chi-square $\mathrm{P}=0.98$ ), or $\mathrm{PDR}$ (chi-square $\mathrm{P}=0.21$ ) when trainees were or were not included.

\section{Discussion}

Our study compared the BBPS with the ADR, SDR, AADR and PDR for all colon segments. We used total BBPS scores as a continuous variable with total scores from 0 to 9 , and we also compared prep categories of poor/fair, good and excellent using the overall BBPS. Because of the limited number of observations with a poor segmental BBPS (segmental BBPS score of 0 ), we combined BBPS scores equivalent to poor and fair together (BBPS scores of $<6$ ) comparing them to scores of good and excellent (BBPS scores $\geq 6$ ). This was based on the Calderwood et al study regarding the adequacy of BBPS in predicting endoscopists' behavior for follow-up intervals, where a total BBPS score $\geq 6$ provided a standardized definition for adequate 10-year follow up [9]. In addition, a recent study showed that a segmental score of 1 has a significantly higher rate of missed adenomas compared with segmental scores of 2 or 3 [11].

We found lower detection rates of adenomas, sessile serrated polyps, advanced adenomas and polyps across all bowel
Table 3 Advanced adenoma detection rate (AADR), adenoma detection rate (ADR) and serrated polyp detection rate (SDR) by colon segment and by bowel prep score

\begin{tabular}{lcc}
\hline Detection rate by segment & Odds ratio & P-value ${ }^{1,2}$ \\
\hline AADR left & 0.9 & 0.65 \\
\hline $95 \% \mathrm{CI}$ & $(0.62-1.29)$ & \\
\hline AADR transverse & 0.37 & 0.04 \\
\hline $95 \% \mathrm{CI}$ & $(0.17-0.80)$ & \\
\hline AADR right & 0.74 & 0.30 \\
\hline $95 \% \mathrm{CI}$ & $(0.49-1.13)$ & \\
\hline ADR left & 1 & 0.98 \\
\hline $95 \% \mathrm{CI}$ & $(0.84-1.20)$ & \\
\hline ADR transverse & 0.8 & 0.21 \\
\hline $95 \% \mathrm{CI}$ & $(0.62-1.04)$ & 0.04 \\
\hline ADR right & 0.79 & 0.64 \\
\hline $95 \% \mathrm{CI}$ & $(0.66-0.94)$ & 0.64 \\
\hline SDR w/ HP left & 0.78 & 0.355 \\
\hline $95 \% \mathrm{CI}$ & $(0.65-0.92)$ & \\
\hline SDR w/ HP transverse & 0.77 & \\
\hline $95 \% \mathrm{CI}$ & $(0.51-1.15)$ & \\
\hline SDR w/ HP right & 0.91 & \\
\hline $95 \% \mathrm{CI}$ & $(0.68-1.21)$ & \\
\hline SDR w/o HP left & 1.18 & \\
\hline $95 \% \mathrm{CI}$ & $(0.75-1.86)$ & \\
\hline SDR w/o HP transverse & 0.77 & \\
\hline $95 \% \mathrm{CI}$ & $(0.44-1.34)$ & \\
\hline SDR w/o HP right & 0.89 & \\
\hline $95 \% \mathrm{CI}$ & & \\
\hline
\end{tabular}

${ }^{1}$ Univariate logistic regression with Boston bowel preparation scale as continuous covariate, ${ }^{2} \mathrm{P}$-values have been adjusted to reflect a false discovery rate of 0.05

CI, confidence interval; SDR $w / H P$, serrated polyp detection rate with hyperplastic polyps; SDR w/o HP, serrated polyp detection rate without hyperplastic polyps

preparation scores as the prep score increased. A score of excellent had lower detection rates for these lesions than a score of good or poor/fair in all colon segments. We also found that a score of excellent in the right colon had a significantly lower ADR than the two other bowel preparation categories. Our results remained consistent even when we adjusted for withdrawal time, age, BMI, presence of diabetes, and sex. The addition of hyperplastic polyps to the serrated polyp detection rate was significant amongst bowel prep classes but was not significant when hyperplastic polyps were removed from the SDR calculation. This is probably because there were more hyperplastic polyps than serrated adenomas. When poor and fair prep score categories were separated out, our results 
Table 4 Advanced adenoma detection rate (AADR), adenoma detection rate (ADR) and serrated polyp detection rate (SDR) by colon segment and by segmental bowel prep score

\begin{tabular}{|c|c|c|c|c|c|c|c|c|c|}
\hline \multirow{2}{*}{$\begin{array}{l}\text { Detection rate } \\
\text { by segment }\end{array}$} & \multicolumn{2}{|c|}{ Poor/Fair ${ }^{2}$} & \multicolumn{2}{|c|}{ Good } & \multicolumn{2}{|c|}{ Excellent } & \multicolumn{2}{|c|}{ Total } & \multirow{2}{*}{$\begin{array}{c}\text { P-value }{ }^{1,3} \\
0.95\end{array}$} \\
\hline & $11 / 245$ & $4.5 \%$ & $45 / 1181$ & $3.8 \%$ & $20 / 565$ & $3.5 \%$ & $76 / 1991$ & $3.8 \%$ & \\
\hline 95\%CI (\%) & $(2.3-7.9)$ & & $(2.8-5.1)$ & & $(2.2-5.4)$ & & $(3.0-4.8)$ & & \\
\hline $\begin{array}{l}\text { AADR } \\
\text { transverse (\%) }\end{array}$ & $2 / 76$ & $2.6 \%$ & $18 / 1179$ & $1.5 \%$ & $3 / 736$ & $0.4 \%$ & $23 / 1991$ & $1.2 \%$ & 0.09 \\
\hline 95\%CI (\%) & $(0.3-9.2)$ & & $(0.9-2.4)$ & & $(0.01-1.2)$ & & $(0.7-1.7)$ & & \\
\hline AADR right (\%) & $7 / 260$ & $2.7 \%$ & $41 / 1228$ & $3.3 \%$ & $8 / 503$ & $1.6 \%$ & $56 / 1991$ & $2.8 \%$ & 0.30 \\
\hline 95\%CI (\%) & $(1.1-5.5)$ & & $(2.4-4.5)$ & & $(0.7-3.1)$ & & $(2.1-3.6)$ & & \\
\hline ADR left (\%) & $41 / 245$ & $16.7 \%$ & $227 / 1181$ & $19.2 \%$ & $100 / 565$ & $17.7 \%$ & $368 / 1991$ & $18.5 \%$ & 0.77 \\
\hline 95\%CI (\%) & $(12.3-22.0)$ & & $(17.0-21.6)$ & & $(14.6-21.1)$ & & $(16.8-20.3)$ & & \\
\hline $\begin{array}{l}\text { ADR transverse } \\
(\%)\end{array}$ & $8 / 76$ & $10.5 \%$ & $144 / 1179$ & $21.2 \%$ & $68 / 736$ & $9.2 \%$ & $220 / 1991$ & $11.1 \%$ & 0.27 \\
\hline 95\%CI (\%) & $(4.7-19.7)$ & & $(10.4-14.2)$ & & $(7.3-11.6)$ & & $(9.7-12.5)$ & & \\
\hline ADR right (\%) & $55 / 260$ & $21.2 \%$ & $258 / 1228$ & $21 \%$ & $73 / 503$ & $14.5 \%$ & $386 / 1991$ & $19.4 \%$ & 0.05 \\
\hline 95\%CI (\%) & $(16.4-26.6)$ & & $(18.8-23.4)$ & & $(11.6-17.9)$ & & $(11.6-21.2)$ & & \\
\hline $\begin{array}{l}\text { SDR w/ HP left } \\
(\%)\end{array}$ & $67 / 245$ & $27.4 \%$ & $253 / 1181$ & $21.4 \%$ & $102 / 565$ & $18.1 \%$ & $422 / 1991$ & $21.2 \%$ & 0.04 \\
\hline 95\%CI (\%) & $(21.9-33.4)$ & & $(19.1-23.9)$ & & $(15.0-21.5)$ & & $(19.4-23.1)$ & & \\
\hline $\begin{array}{l}\text { SDR w/ HP } \\
\text { transverse (\%) }\end{array}$ & $3 / 76$ & $4 \%$ & $55 / 1179$ & $4.7 \%$ & $24 / 736$ & $3.3 \%$ & $88 / 1991$ & $4.4 \%$ & 0.49 \\
\hline 95\%CI (\%) & $(0.8-11.1)$ & & $(3.5-6.0)$ & & $(2.1-4.8)$ & & $(3.6-5.4)$ & & \\
\hline $\begin{array}{l}\mathrm{SDR} w / \mathrm{HP} \\
\text { right (\%) }\end{array}$ & $17 / 260$ & $6.5 \%$ & $80 / 1228$ & $6.5 \%$ & $28 / 503$ & $5.6 \%$ & $125 / 1991$ & $6.3 \%$ & 0.81 \\
\hline 95\%CI (\%) & $(3.9-10.3)$ & & $(5.2-8.0)$ & & $(3.7-8.0)$ & & $(5.3-7.4)$ & & \\
\hline $\begin{array}{l}\text { SDR w/o HP } \\
\text { left (\%) }\end{array}$ & $2 / 245$ & $0.8 \%$ & $35 / 1181$ & $3 \%$ & $13 / 565$ & $2.3 \%$ & $50 / 1991$ & $2.5 \%$ & 0.44 \\
\hline 95\%CI (\%) & $(0.1-2.9)$ & & $(2.1-4.1)$ & & $(1.2-3.9)$ & & $(1.9-3.3)$ & & \\
\hline $\begin{array}{l}\text { SDR w/o HP } \\
\text { transverse (\%) }\end{array}$ & $1 / 76$ & $1.3 \%$ & $30 / 1179$ & $2.5 \%$ & $12 / 736$ & $1.6 \%$ & $43 / 1991$ & $2.2 \%$ & 0.51 \\
\hline 95\%CI (\%) & $(0.0-7.1)$ & & $(1.7-3.6)$ & & $(0.9-2.8)$ & & $(1.6-2.9)$ & & \\
\hline $\begin{array}{l}\text { SDR w/o HP } \\
\text { right (\%) }\end{array}$ & $14 / 260$ & $5.4 \%$ & $50 / 1228$ & $4.1 \%$ & $21 / 503$ & $4.2 \%$ & $85 / 1991$ & $4.3 \%$ & 0.83 \\
\hline 95\%CI (\%) & $(3.0-8.9)$ & & $(3.0-5.3)$ & & $(2.6-6.3)$ & & $(3.4-5.3)$ & & \\
\hline
\end{tabular}

${ }^{1}$ Chi-squared test, ${ }^{2}$ Categories were combined because of the limited number of observations with a segmental poor bowel prep score (Boston bowel preparation scale $=0),{ }^{3}$-values have been adjusted to reflect a false discovery rate of 0.05

CI, confidence interval; SDR w/ HP, serrated polyp detection rate with hyperplastic polyps; SDR w/o HP, serrated polyp detection rate without hyperplastic polyps

remained consistent (Supplemental Table 1). Furthermore, as a measure of the total polyps per colonoscopy, the relative polyp rate per colonoscopy (RPR) was also analyzed using the poor/fair, good and excellent categories and adjusted for withdrawal time (Supplemental Table 2) with a higher RPR for poor/fair preps compared with good preps (RPR 0.80, 95\%CI 0.70-0.91; $\mathrm{P}<0.001$ ) and excellent preps (RPR 0.71, 95\%CI 0.61-0.83; $\mathrm{P}<0.001$ ).

It is well known that adenomatous polyps are precursors of colorectal cancer (CRC). The detection and removal of colon polyps has been shown to decrease the incidence of CRC [13-15]. The ADR is an important predictor of interval
CRC and is an important quality metric with a current benchmark of above 25\% [13,14-16]. Higher ADRs are associated with a reduced risk of both proximal and distal cancers in men and women [13]. Bowel preparation quality is also another important colonoscopy quality indicator. Poor bowel preparation has been associated with prolonged procedure times, a higher risk of complications and incomplete procedures, and has been shown to reduce the detection of colonic lesions [17-18]. One study reported an adenoma miss rate of $42 \%$ for colonoscopies with suboptimal preparation repeated within three years after the index colonoscopy [17]. 
Table 5 Logistic regression model ${ }^{1,3}$ results for total Boston bowel preparation scale scores and overall advanced adenoma detection rate (AADR), adenoma detection rate (ADR), serrated polyp (with hyperplastic polyps) detection rate (SDR w/ HP), serrated polyp (without hyperplastic polyps) detection rate (SDR w/o HP), and polyp detection rate (PDR) $(\mathrm{n}=1965)$

\begin{tabular}{lcc} 
Overall detection rate & Odds ratio & P-value $^{1,2}$ \\
\hline AADR & 0.88 & 0.11 \\
$95 \% \mathrm{CI}$ & $(0.78-0.998)$ & \\
ADR & 0.9 & 0.01 \\
$95 \% \mathrm{CI}$ & $(0.84-0.96)$ & \\
SDR (w/ HP) & 0.89 & 0.01 \\
$95 \% \mathrm{CI}$ & $(0.83-0.96)$ & \\
SDR (w/o HP) & 0.96 & 0.64 \\
$95 \% \mathrm{CI}$ & $(0.86-1.08)$ & 0.02 \\
PDR & 0.85 & \\
$95 \% \mathrm{CI}$ & $(0.80-0.91)$ &
\end{tabular}

${ }^{1}$ Adjusted for withdrawal time ( $\leq 6 \mathrm{~min}$ vs. $>6 \mathrm{~min}$ ), age, body mass index, diabetes status and sex, ${ }^{2} \mathrm{P}$-values have been adjusted to reflect a false discovery rate of $0.05,{ }^{3}$ Univariate logistic regression with Boston bowel preparation scale as a continuous covariate

CI, confidence interval

Another prospective observational study found that colonoscopies with a segmental BBPS of 1 have a higher miss rate of adenomas larger than $5 \mathrm{~mm}$ compared with segmental scores of 2 or 3 [11]. Current guidelines recommend that bowel preparation must be adequate in at least $85 \%$ of screening colonoscopies to allow the use of recommended surveillance or screening intervals [13]. The BBPS has been established as a validated preparation score for standardizing the definition of the level of cleanliness amongst endoscopists [9]. Unlike the Aronchick or Ottawa Bowl Prep scores, which assess the quality of the bowel prep prior to cleaning and suctioning, the BBPS has been shown to have excellent intra- and interobserver reliability for each colonic segment after cleaning [19]. While bowel preparation is an important determinant of the quality of a colonoscopy, it has become apparent that the relationship between quality and the detection of lesions in clinical practice is more complex. Several studies have shown that there is not necessarily an association between bowel preparation quality and ADR [5-7,20-22].

Clark et al [5], using the Aronchick bowel preparation scale for standardization, performed a meta-analysis and systematic review of the impact of bowel preparation on adenoma detection and found that ADRs were higher in either excellent/good or fair quality prep compared to low quality preps. However, there was no significant difference between intermediate quality (fair) preps and high quality (excellent/good) preps. In addition, there was no difference in the ADRs between good and excellent preps. Another study using the New Hampshire Colonoscopy registry with descriptive prep quality scores found no difference in the total or proximal ADR or the SDR between excellent/good and fair preps [7]. In addition, although Sherer et al found
Table 6 Logistic regression model ${ }^{1,3}$ results for advanced adenoma detection rate (AADR), adenoma detection rate (ADR) and serrated polyp, including hyperplastic polyps, detection rate (SDR) by colon preparation and colon segment $(\mathrm{n}=1965)$

\begin{tabular}{|c|c|c|}
\hline Detection rate by segment & Odds ratio & P-value ${ }^{1,2}$ \\
\hline AADR left & 0.89 & 0.65 \\
\hline $95 \%$ CI & $(0.61-1.30)$ & \\
\hline AADR transverse & 0.37 & 0.05 \\
\hline $95 \%$ CI & $(0.17-0.83)$ & \\
\hline AADR right & 0.74 & 0.30 \\
\hline $95 \% \mathrm{CI}$ & $(0.48-1.13)$ & \\
\hline ADR left & 0.99 & 0.96 \\
\hline 95\%CI & $(0.82-1.20)$ & \\
\hline ADR transverse & 0.83 & 0.31 \\
\hline 95\%CI & (0.64-1.08) & \\
\hline $\mathrm{ADR}$ right & 0.79 & 0.04 \\
\hline 95\%CI & $(0.65-0.95)$ & \\
\hline SDR w/ HP left & 0.76 & 0.02 \\
\hline $95 \% \mathrm{CI}$ & $(0.64-0.91)$ & \\
\hline SDR w/ HP transverse & 0.74 & 0.30 \\
\hline $95 \% \mathrm{CI}$ & $(0.49-1.12)$ & \\
\hline SDR w/ HP right & 0.89 & 0.61 \\
\hline $95 \%$ CI & $(0.66-1.20)$ & \\
\hline SDR w/o HP left & 1.17 & 0.64 \\
\hline 95\%CI & $(0.74-1.86)$ & \\
\hline SDR w/o HP transverse* & 0.7 & 0.37 \\
\hline $95 \% \mathrm{CI}$ & $(0.40-1.23)$ & \\
\hline SDR w/o HP right & 0.85 & 0.51 \\
\hline 95\%CI & $(0.59-1.20)$ & \\
\hline
\end{tabular}

${ }^{1}$ Adjusted for withdrawal time ( $\leq 6 \mathrm{~min}$ vs. $>6 \mathrm{~min}$ ), age, body mass index, diabetes status and sex, ${ }^{2} \mathrm{P}$-values are adjusted to reflect a false discovery rate of $0.05,{ }^{*}$ No observations had a withdrawal time $\leq 6 \mathrm{~min}$. Therefore withdrawal time was not adjusted, ${ }^{3}$ Univariate logistic regression with Boston bowel preparation scale as a continuous covariate

$C I$, confidence interval; SDR $w / H P$, serrated polyp detection rate with hyperplastic polyps; SDR w/o HP, serrated polyp detection rate without hyperplastic polyps

poor preps had a lower detection rate of diminutive adenoma $(\leq 5 \mathrm{~mm})$ and advanced adenomas, there was no statistical difference in the ADRs of diminutive, small (5-9 mm) and advanced adenomas in colonoscopies with fair preps versus good/excellent preps [20]. Another study using the Aronchick scale found that, while fair and poor preparations had significantly lower colonoscopy completion rates, there was no difference in the ADR between bowel preparations. Colonoscopies with fair preparation were more likely to find at least one polyp than those with excellent or poor preps [21]. Finally, Calderwood et al used the BBPS to categorize bowel cleanliness and found that ADR and PDR decreased as the degree of bowel cleanliness increased from good to excellent 
[6]. These authors found that a segment score of 2 compared with 3 was associated with higher PDR and ADR in all segments of the colon [6].

Two prior studies had found no difference in the SDR in the proximal colon amongst a preparation score of poor, fair and excellent/good [7,22]. In our study, the overall SDR was higher with poor/fair scores than in other prep scores; and in the left colon, a score of poor/fair had a significantly higher SDR (when hyperplastic polyps were included) compared with the other two bowel preparation categories.

There are several reasons why an excellent prep may have a lower rate of detection of colonic lesions [6,7]. One reason is that residual stool may help the endoscopist pay attention to the mucosa and thus identify lesions, which may otherwise not be seen. In the case of serrated polyps, residual stool may attach to the mucus caps and make these polyps more conspicuous in less clean colons. In addition, it is possible that the quality of inspection decreases at the best level of bowel preparation because the endoscopist has a false sense of confidence. Another theory is that endoscopists may rate a colon preparation as excellent when no polyps are found [6].

Although several studies have previously reported a nonlinear relationship with prep quality [5-7], to the best of our knowledge, this is the first study to look at the effect of bowel preparation on detection rates in each colon segment using the BBPS. There are other strengths of our study. We used a prep scoring system, the BBPS, which has been validated with consistent intra- and interobserver variability. In addition, we had the pathological data available for each colonoscopy in a single tertiary institution with uniform agreement amongst pathologists on the definition of sessile serrated polyps. Our results remained consistent using the BBPS scores categorized as poor/fair (BBPS score of 0-5), good (BBPS scores of 6 and 7) and excellent (BBPS scores of 8 and 9), as well as using the total BBPS as a continuous variable. We adjusted our results using withdrawal time, age, BMI, presence of diabetes mellitus and sex, and our results remained consistent, with detection rates of adenomas and polyps decreasing as BBPS scores increased. Our results demonstrate generalizability, in that some recent studies have provided similar messages, also suggesting that ADR does not necessarily increase as the colon prep quality increases. It is important to note that this phenomenon is observed despite different bowel preparation scoring methods. We acknowledge the limitations of this single-center study. Other potential limitations of our study are its retrospective nature and small sample size compared with similar studies. We also acknowledge that there is only a small difference in overall ADR and PDR across bowel prep scores; nevertheless, the change was statistically significant. In addition, we did not collect data on any techniques, such as water infusion or image enhancement techniques that may have been used by endoscopists to improve adenoma detection.

Our findings have implications for screening and surveillance colonoscopies. In patients with excellent preps, care must be taken to meticulously inspect the mucosa. Colonoscopists must not be falsely reassured that an adequate inspection has occurred simply because of a high quality colonic preparation. Our findings reinforce the need for meticulous inspection regardless of the prep quality.

In conclusion, using the BBPS score, we have shown that the ADR, SDR with hyperplastic polyps, and PDR significantly decrease as the bowel preparation quality increases.

\section{Summary Box}

\section{What is already known:}

- Inadequate colon preparation for colonoscopies leads to a lower adenoma detection rate

\section{What the new findings are:}

- Using the Boston bowel preparation scale score, we show that the adenoma detection rate, serrated polyp detection rate with hyperplastic polyps, and polyp detection rate significantly decrease as the bowel preparation quality increases

- A possible explanation for this unexpected discrepancy may be related to longer and better visualization of the mucosa when cleansing and suctioning is necessary

\section{References}

1. Froehlich F, Wietlisbach V, Gonvers JJ, Burnand B, Vader JP. Impact of colonic cleansing on quality and diagnostic yield of colonoscopy: the European Panel of Appropriateness of Gastrointestinal Endoscopy European multicenter study. Gastrointest Endosc 2005;61:378-384.

2. Martin D, Walayat S, Ahmed Z, et al. Impact of bowel preparation type on the quality of colonoscopy: a multicenter communitybased study. J Community Hosp Intern Med Perspect 2016;6:31074.

3. Rex DK, Imperiale TF, Latinovich DR, Bratcher LL. Impact of bowel preparation on efficiency and cost of colonoscopy. Am J Gastroenterol 2002;97:1696-1700.

4. Aranda-Hernández J, Hwang J, Kandel G. Seeing better-Evidence based recommendations on optimizing colonoscopy adenoma detection rate. World J Gastroenterol 2016;22:1767-1778.

5. Clark BT, Rustagi T, Laine L. What level of bowel prep quality requires early repeat colonoscopy: systematic review and metaanalysis of the impact of preparation quality on adenoma detection rate. Am J Gastroenterol 2014;109:1714-1723.

6. Calderwood AH, Thompson KD, Schroy PC $3^{\text {rd }}$, Lieberman DA, Jacobson BC. Good is better than excellent: bowel preparation quality and adenoma detection rates. Gastrointest Endosc 2015;81:691-699.

7. Anderson JC, Butterly LF, Robinson CM, Goodrich M, Weiss JE. Impact of fair bowel preparation quality on adenoma and serrated polyp detection: data from the New Hampshire colonoscopy registry by using a standardized preparation-quality rating. Gastrointest Endosc 2014;80:463-470.

8. Calderwood AH, Jacobson BC. Comprehensive validation of the Boston Bowel Preparation Scale. Gastrointest Endosc 2010;72:686-692. 
9. Calderwood AH, Schroy PC $3^{\text {rd }}$, Lieberman DA, Logan JR, Zurfluh M, Jacobson BC. Boston Bowel Preparation Scale scores provide a standardized definition of adequate for describing bowel cleanliness. Gastrointest Endosc 2014;80:269-276.

10. Bechtold ML, Mir F, Puli SR, Nguyen DL. Optimizing bowel preparation for colonoscopy: a guide to enhance quality of visualization. Ann Gastroenterol 2016;29:137-146.

11. Clark BT, Protiva P, Nagar A, et al. Quantification of adequate bowel preparation for screening or surveillance colonoscopy in men. Gastroenterology 2016;150:396-405.

12. Bosman FT, Carneiro F, Hruban RH, et al. WHO classification of tumours of the digestive system. The International Agency for Research on Cancer. Thiese. $4^{\text {th }}$ edition. 2010.

13. Rex DK, Schoenfeld PS, Cohen J, et al. Quality indicators for colonoscopy. Gastrointest Endosc 2015;81:31-53.

14. Pohl H, Robertson DJ. Colorectal cancers detected after colonoscopy frequently result from missed lesions. Clin Gastroenterol Hepatol 2010;8:858-864.

15. Coe SG, Wallace MB. Assessment of adenoma detection rate benchmarks in women versus men. Gastrointest Endosc 2013;77:631-635.

16. Kaminski MF, Regula J, Kraszewska E, et al. Quality indicators for colonoscopy and the risk of interval cancer. $N$ Engl $J$ Med 2010;362:1795-1803.

17. Lebwohl B, Kastrinos F, Glick M, Rosenbaum AJ, Wang T, Neugut AI. The impact of suboptimal bowel preparation on adenoma miss rates and the factors associated with early repeat colonoscopy. Gastrointest Endosc 2011;73:1207-1214.

18. Harewood GC, Sharma VK, de Garmo P. Impact of colonoscopy preparation quality on detection of suspected colonic neoplasia. Gastrointest Endosc 2003;58:76-79.

19. Stijn J.B. Van Weyenberg. Grading the quality of bowel preparation. VJGIEN 2014;1:615-618.

20. Sherer EA, Imler TD, Imperiale TF. The effect of colonoscopy preparation quality on adenoma detection rates. Gastrointest Endosc 2012;75:545-553.

21. Rai T, Navaneethan U, Gohel T, et al. Effect of quality of bowel preparation on quality indicators of adenoma detection rates and colonoscopy completion rates. Gastroenterol Rep (Oxf) 2016;4:148-153.

22. de Wijkerslooth TR, Stoop EM, Bossuyt PM, et al. Differences in proximal serrated polyp detection among endoscopists are associated with variability in withdrawal time. Gastrointest Endosc 2013;77:617-623.

\section{Supplemental Table}

Supplemental Table 1 Overall adenoma detection rate (ADR), advanced adenoma detection rate (AADR), serrated polyp detection rate (SDR), and polyp detection rate (PDR) by bowel prep score

\begin{tabular}{|c|c|c|c|c|c|c|c|c|c|c|c|}
\hline \multirow{2}{*}{$\begin{array}{l}\text { Overall detection rate } \\
\operatorname{AADR}(\%)\end{array}$} & \multicolumn{2}{|c|}{ Poor } & \multicolumn{2}{|l|}{ Fair } & \multicolumn{2}{|c|}{ Good } & \multicolumn{2}{|c|}{ Excellent } & \multicolumn{2}{|l|}{ Total } & \multirow{2}{*}{$\frac{\text { P-value }^{1}}{0.081}$} \\
\hline & $10 / 134$ & $(7.5)$ & $21 / 272$ & $(7.7)$ & $87 / 1033$ & $(8.4)$ & $27 / 552$ & $(4.9)$ & $145 / 1991$ & $(7.3)$ & \\
\hline 95\%CI (\%) & $(3.6-13.3)$ & & $(4.8-11.6)$ & & $(6.8-10.3)$ & & $(3.3-7.0)$ & & $(6.2-8.5)$ & & \\
\hline $\operatorname{ADR}(\%)$ & $47 / 134$ & $(35.1)$ & $115 / 272$ & $(42.3)$ & $414 / 1033$ & $(40.1)$ & $170 / 552$ & $(30.8)$ & $746 / 1991$ & $(37.5)$ & 0.001 \\
\hline 95\%CI (\%) & $(27.0-43.8)$ & & $(36.3-48.4)$ & & $(37.1-43.1)$ & & $(27.0-34.8)$ & & $(35.3-39.6)$ & & \\
\hline SDR w/ HP (\%) & $40 / 134$ & (29.9) & $89 / 272$ & $(32.7)$ & $302 / 1033$ & $(29.2)$ & $124 / 552$ & $(22.5)$ & $555 / 1991$ & $(27.9)$ & 0.006 \\
\hline 95\%CI (\%) & $(22.3-38.4)$ & & $(27.2-38.7)$ & & $(26.5-32.1)$ & & $(19.1-26.2)$ & & $(25.9-29.9)$ & & \\
\hline SDR w/o HP (\%) & $5 / 134$ & (3.7) & $24 / 272$ & $(8.8)$ & $93 / 1033$ & $(9.0)$ & $39 / 552$ & $(7.1)$ & $161 / 1991$ & $(8.1)$ & 0.135 \\
\hline $95 \% \mathrm{CI}(\%)$ & $(1.2-8.5)$ & & $(5.7-12.8)$ & & $(7.3-10.9)$ & & $(5.1-9.5)$ & & $(6.9-9.4)$ & & \\
\hline PDR (\%) & $84 / 134$ & $(62.7)$ & $171 / 272$ & $(62.9)$ & $599 / 1033$ & $(58.0)$ & $265 / 552$ & $(48.0)$ & $1119 / 1991$ & $(56.2)$ & $\begin{array}{c}< \\
0.0001\end{array}$ \\
\hline 95\%CI (\%) & $(53.9-70.9)$ & & $(56.8-68.6)$ & & $(54.9-61.0)$ & & $(43.8-52.3)$ & & $(54.0-58.4)$ & & \\
\hline
\end{tabular}

${ }^{1}$ Chi-square test

CI, confidence interval; SDR $w /$ HP, serrated polyp detection rate with hyperplastic polyps; SDR w/o HP, serrated polyp detection rate without hyperplastic polyps

Supplemental Table 2 Relative polyp rate per colonoscopy

\begin{tabular}{|c|c|c|}
\hline BBPS category & RPR & $(95 \% \mathrm{CI})$ \\
\hline Excellent & 0.71 & $(0.61-0.83)$ \\
\hline Good & 0.80 & $(0.70-0.91)$ \\
\hline Poor/Fair & \multicolumn{2}{|c|}{ Reference (1.0) } \\
\hline \multicolumn{3}{|c|}{ 1. Adjusted for withdrawal time, age, and sex } \\
\hline \multicolumn{3}{|c|}{ 2. The Poisson model was adjusted for over dispersion using scaled deviance } \\
\hline
\end{tabular}

